\title{
Discussion on the issue pilot air refueling aircraft
}

\author{
Chunguang Wang ${ }^{1, a}$, Xiujuan Liü ${ }^{2, a}$, Xin Wang ${ }^{3, a}$, Luofeng Lin ${ }^{4, a}$ \\ Zhigang Dong ${ }^{5, a}$, Changlong zhou ${ }^{6, a}$ \\ Aviation University of Air Force, Changchun, China
}

723704537@qq.com

Keywords: Aerial refueling; Airspace; Rendezvous;Docking

\begin{abstract}
Aerial refueling means by the loading of fuel in flight aircraft refueling systems use devices to other aircraft refueling. Currently, the aerial refueling system mainly has two hard pipe refueling system and refueling hose system. By air refueling, it is possible to increase the range and combat radius of the aircraft, increase payload and cargo capacity, prolong life.
\end{abstract}

\section{Introduction}

Organization of air refueling, pilots have a special emphasis on the ability to prepare a good pilot. Come unsuccessful, in most cases is due to problems caused by pilot rendezvous terms. Therefore, careful study and do aerial refueling pilot work is very important. Air refueling airspace should focus on the choice, choose the way of aerial refueling, aerial refueling implementation process and other issues.

\section{Air refueling airspace choice}

Selected refueling airspace is to ensure its own security, the key to economic and rational use of aerial refueling capability, the successful completion of combat mission aerial refueling aircraft. Refueling airspace must be selected according to the actual needs of combat to determine, the choice should fully consider the following factors;

Fuel refueling aircraft and refueling aircraft of consumption.Refueling aircraft at the time to carry out combat missions, flight altitude, speed, and atmospheric temperature, humidity is different, the fuel consumption must be different. The best is when you replenish its fuel consumption to a certain extent, such as supplementary premature, to increase flight refueling aircraft little; add too late, once the abnormal situation will be difficult to dispose of. Normally in the aircraft fuel consumption by more than half the oil for aerial refueling. Select refueling points and refueling process should also consider serving their own refueling aircraft fuel consumption, to ensure that refuel aircraft after the completion of the air refueling mission, to have enough fuel to return to the station or other nearby airports.

Security refueling aircraft, hidden.For aerial refueling, the security is paramount. Because refueling aircraft are mostly converted from transports and bombers made, bulky, poor mobility, defense capacity is weak. Come on aircraft are not self-defense weapons, refueling aircraft and routes can not be arbitrarily changed, once the enemy was informed, vulnerable to interception. Even partners refuel fighter aircraft modified, because carrying a refueling pod, mobility has also been greatly affected. Secondly, the refueling process longer than a few minutes off from convergence to be up to 40 minutes, and the two aircraft docking and oil process, the absolute prohibition of any maneuver. If at this time was an enemy attack, the greatest risk. Therefore, for safety reasons, in general, small-scale conflict, refueling aircraft away from the danger zone, to avoid ground small-caliber weapons shot high, choose a safe height in the air. US Air Force at a height of $3400 \mathrm{~m}$ or less rarely performed aerial refueling. There are indications that future wars against each other refueling combat aircraft will be an important task. The Gulf War, to carry out tasks in the border in northern Iraq refueling aircraft pilots often see Iraqi antiaircraft artillery opened fire on the air, and therefore, the implementation of aerial refueling, refueling point must be selected in the safe area, to minimize the possibility of being discovered by the enemy. 
Refueling airspace meteorological conditions.Good weather conditions are the basic conditions for the smooth conduct aerial refueling. Due to the implementation process in aerial refueling, refueling planes and refueling aircraft must rendezvous, docking, in order to refuel, so to choose the excellent weather conditions as refueling airspace airspace. Come airspace must stay away from thunderstorm zones, better visibility, no strong jolt, no rain and fog, fog, dust storms and other inclement weather, while also considering the sun found that the impact of air planes visual search. While refueling, it can boot by positioning system equipment refueling aircraft and refueling aircraft safety join, but after two planes to reach a certain distance, visual observation is still the only means of refueling aircraft and refueling aircraft docking, in order to make refueling aircraft can find the distance from the refueling aircraft, safe and successful rendezvous and docking, according to experience, refueling airspace visibility should be at least 8 to $10 \mathrm{~km}$ or more, otherwise it will be difficult to ensure the safety of aerial refueling.

Come airspace should be obvious signs.Location of refueling aircraft refueling airspace and refueling aircraft, are very important, not only meet the basic conditions for both sides accurately, but also timely refueling aircraft in the air for a long time waiting for track inspection, the exact position of holding its own foundation. For refueling aircraft and for aircraft refueling rendezvous, refueling airspace beneath a clear, fixed, easily recognizable landmark, it is beneficial for refueling aircraft, command guidance.

In the case of command guidance is not timely or disturbed by oil aircraft can be based on clearly marked, find refueling aircraft. Command, communications were disrupted, undermined in modern warfare is prone, once that happens, you can rely on obvious landmarks pilot.

Aerial refueling economy.Modern warfare, long-range strike has become an increasingly important form of warfare, and thus dependence on air refueling aircraft is also increasing. When long-range combat, air refueling may be more than one, such as the war in Afghanistan, took off from Whiteman Air Force Base B-2A stealth bombers carry out a combat mission to go through 44 hours of continuous flight, except landed at Diego Garcia ground fueling island, but also the need for the whole nine aerial refueling, in addition, $\mathrm{B}-52 \mathrm{H}$ and $\mathrm{B}-1 \mathrm{~B}$ aircraft taking off and landing from the forefront of the airport shuttle also need refueling 2 to 3 times. There must be many times more than refueling refueling point. To ensure air refueling of the economy, distance between each refueling point should be a scientific basis, it is necessary to ensure that the aircraft can obtain the necessary oil life time, but also to minimize the number of refueling, saving sorties refueling aircraft, the use of minimum refueling aircraft to maximize operational effectiveness.

Select refueling mode.Refueling aircraft and collaborative refueling aircraft, is the key to successful implementation with aerial refueling, coordination is not good, not only can not complete the refueling mission, and may endanger air safety. Refueling aircraft and collaborative refueling aircraft, with different ways, each with different characteristics, needs practical manner based on rational use of refueling operations.

With the formula.With the need to refuel aircraft fueling and refueling aircraft in one formation, flying along the same route. When the aircraft by fuel oil consumption to a certain extent, refueling aircraft will be in place for the refueling en route refueling aircraft. With the type of filling generally applicable to large-scale to small fighter aircraft refueling refueling refueling way this first appeared in combat, still in use, its advantages are: easy refueling position control, no two aircraft rendezvous time consuming and relatively easy collaboration to ensure more reliable. Its shortcomings are: the use of accompanying refueling, refueling aircraft invalid long flight time, wasted fuel economy is poor. In addition, two different types of aircraft flying in formation, its flight performance must be similar, otherwise it will increase the difficulty associated with flying, affect the play fighter speed performance.

Round formula.On a predetermined route refueling aircraft, the selected plurality of refueling point, refueling planes and refueling aircraft at the agreed rendezvous at this point in time, for aerial refueling. After refueling is completed, from each other, they carry out their mission, which is called will be fit for a variety of different refueling aircraft refueling aircraft refueling. Refueling aircraft and aircraft refueling rendezvous can select the following two methods. 
First, the relatively parallel method. As shown in Figure 1, refueling aircraft and refueling aircraft while flying to the opposite designated rendezvous point. Two smaller aircraft to maintain height difference to the air search found each other. When the two aircraft to reach a certain distance from each other to find and confirm, for refueling aircraft near $180^{\circ}$ turn, so that the direction of flight and refueling aircraft consistent refueling located behind the rear or side of the aircraft, refuel and then occupy the position. Under normal circumstances in order to prevent a collision, refueling aircraft below the refueling aircraft, refueling aircraft entered from the rear side. This method is suitable for refueling planes and refueling aircraft farther apart, and the flight heading difference near $180^{\circ}$ use.
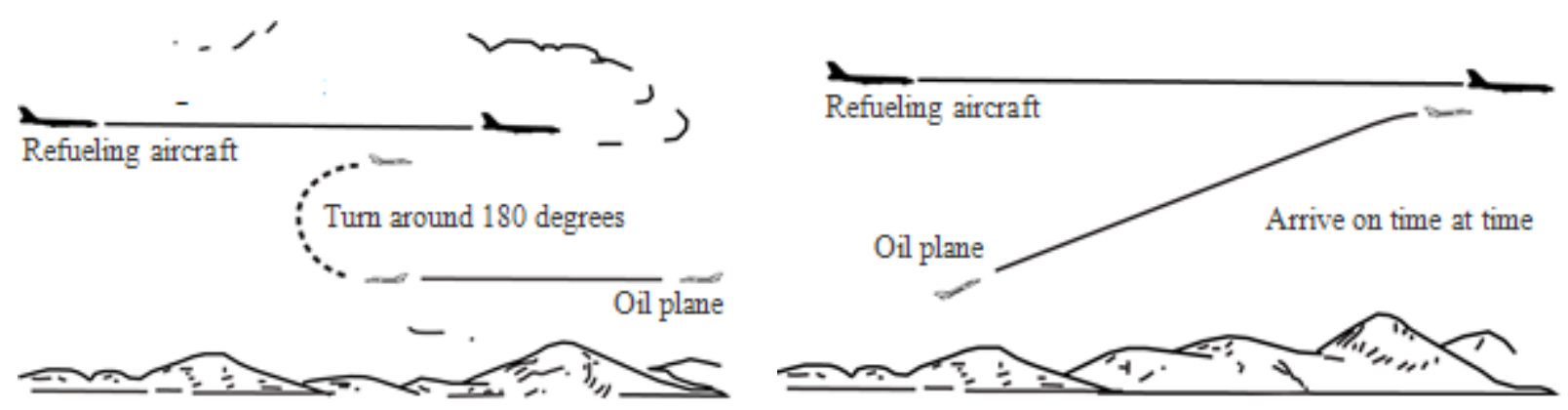

Fig1. Relative parallel method schemati

Fig2.Law in place on time rendezvous method schematic

Second, the law in place on time. When refueling planes and refueling aircraft flight routes closer, flight heading differ by less than $90^{\circ}$, the use of such methods rendezvous. As shown in Figure 2, when the rendezvous, refueling planes and refueling aircraft based on the determined position refueling, according to the command or meet the agreed time, arrive refueling rendezvous airspace. This method requires that both sides can accurately identify the location and identification of refueling, arrive airspace position and ensure mutual unimpeded. After two aircraft approaching, adopt a gradual approach near occupy refueling location. The closer the two aircraft, the smaller the relative velocity should, while maintaining a certain height difference, in order to avoid a collision.

Both methods meet either by oil refueling aircraft from the aircraft independently, it can also be done in command guidance airborne early warning command and control aircraft or ground command post.

Aerial wait formula. Refueling aircraft on scheduled routes by aircraft flying at or near oil airspace hovering flight, when the oil reaches the aircraft to carry out aerial refueling is called the air waiting for ceremony. Come this way to be used for supporting the implementation of air warfare, patrol, rescue and other special mission aircraft, in particular, support helicopter operations. The advantages of this approach are: refueling aircraft relatively fixed range of activities to facilitate refueling aircraft for aerial search found; an aircraft may have been several large refueling aircraft refueling aircraft in the past in the same location, reducing the airspace due to the refueling aircraft to and from the shuttle caused by congestion, which will help air scheduling; pilot in command guidance and protection, just focus on the care oil aircraft, simpler than will fit. The disadvantage of this approach are: refueling aircraft circling in the air a long time, is likely to expose the target, it may have been an enemy attack, it is not conducive to the safety of air refueling aircraft.

In addition to the above-mentioned three methods, but also there are some other ways refueling. Board Boer War experience over the years had shown that the use in combat, with style, will fit and aerial refueling wait mode type, etc. are likely to be used in the formulation which requires air refueling program, according to the nature of the battlefield situation and tasks, refueling aircraft and by the specific circumstances of the resident oil aircraft, air force deployment and command coordination and other aspects of a comprehensive analysis of aerial refueling flexibility in determining the specific force formula, the only way to achieve the best operational results.

Implementation of aerial refueling.Aerial refueling process is under the joint with refueling aircraft and refueling aircraft completed. Refueling aircraft and refueling aircraft refueling process is 
completed, the need to constantly adjust aircraft attitude, speed, altitude and heading. When refueling aircraft and refueling aircraft are far apart, the relative velocity of the aircraft fast, accurate measurement is more difficult to judge the position of the air; when refueling planes and refueling aircraft docking process, the distance between the aircraft, the spacing, the height difference is very small, for pilot judgment, disposition time is very short, requires the pilot to judge the situation, the disposal must be very accurate, and timely; during refueling, refueling aircraft and by the movement of the oil must be completely consistent with the aircraft, the relative velocity is zero, in order to carry out stable refueling. Therefore, aerial refueling operation process is complex, the pilot must have superb flying skills, and bold but cautious, to complete aerial refueling.

Rendezvous phase.Aerial refueling rendezvous is the first stage, only the refueling of aircraft and aircraft refueling rendezvous on time, in order to carry out the work after each phase. The tasks of different types of aircraft, different stations, different properties of various types of aircraft, flight routes, flight altitude, airspeed and out of time is not the same, in addition to taking the syndrome refueling way, the other way for aerial refueling all We need to meet. In order to ensure aircraft and refueling aircraft refueling rendezvous success in the air, in the development of the air refueling program, it must be clear aerial refueling rendezvous point (or rendezvous airspace). When the air emergency, may also be appointed on an interim commander rendezvous point (or rendezvous airspace). Weather conditions either case, you need to make refueling aircraft and refueling aircraft pilots clear rendezvous point (or rendezvous airspace) and meet the specific location of the region.

Docking phase.Refueling aircraft and refueling aircraft docking is the key to a successful completion of aerial refueling missions. Docking process more complex, safety pressure, the slightest mistake could endanger flight safety. Examples from the previous refueling, the flight accident aerial refueling process, mostly in the docking phase. Therefore, when the organization of air refueling, docking is both safe and secure to ensure flight safety needs, but also to complete the required air refueling missions. Butt stage refueling aircraft and refueling aircraft have different actions. Refueling aircraft maneuvers are:

Release filler tube. Conduct refueling aircraft refueling pipe release time usually after refueling aircraft and refueling aircraft successfully rendezvous, arrived at the designated location remained stable flight. We must maintain a straight line straight flight refueling aircraft refueling pipe release, and flight speed compliance. After the release of refueling aircraft refueling pipe, stable flight, keeping prescribed flight Moroto, and put his flight Moroto communicated to the refueling aircraft.

Refueling refueling aircraft for refueling aircraft to observe and carry out the necessary command, guidance, reminding safe action refueling planes attention. Refuel aircraft after completing the operation, in accordance with the planned flight route flight. In this case, the state is the key to a stable flight refueling of aircraft that can be successfully docked steady flight refueling aircraft, and create favorable conditions, but help to ensure safety. If the state is not stable enough flight refueling itself, docking refueling aircraft will be very difficult. Docking and refueling aircraft during refueling of the aircraft shown in Figure 3.

Come on stage.After the successful docking, refueling aircraft and aerial refueling aircraft to begin refueling. Refueling process is automatic, but also manual intervention, control the number of aerial refueling. Refueling process is controlled by the monitoring device on refueling aircraft, refueling aircraft and pilots refueling aircraft is mainly to maintain a good flight status and flight routes. The length of time depends on how much air refueling refueling requires 5 to 8 minutes under normal circumstances. Refueling aircraft must maintain a refueling aircraft to stay longer in a position, for refueling aircraft pilots is relatively long. Because refueling interval between aircraft and refueling aircraft, distance, height difference is very small, the need for timely discover and correct deviations, and always maintain the relative displacement of the two aircraft is zero. 


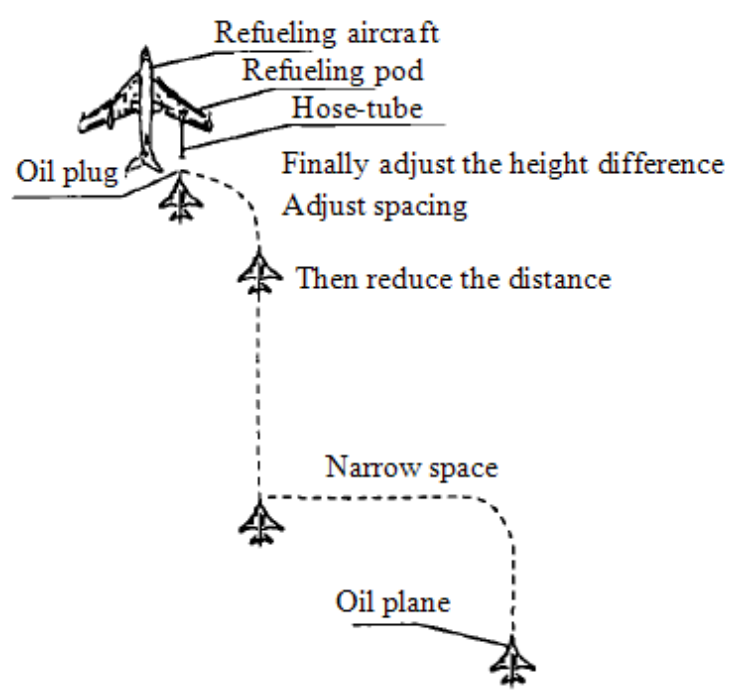

Fig3. Docking schematic stage.

Exit stage.After the completion of aerial refueling, fuel monitoring equipment immediate display, bright lights, suggesting the end of the aerial refueling work. Under normal circumstances, should be based on the monitoring device indicates the end of aerial refueling air refueling, and sometimes also in accordance with the commander's command to end the aerial refueling. Come on stage after the completion of the exit, continue to maintain the original flight refueling flight, ready to follow refueling aircraft refueling. If there is no follow-refueling aircraft, etc. after refueling aircraft security detachment to recover fuel hose, according to the flight plan or direct instruction to fly other airspace or return to base.

\section{Summary}

Aerial refueling process consists of rendezvous, docking, refueling and out in four stages, each stage different but linked, before a stage to create the conditions for the latter stages, before and after the two stages closely dovetail with each other, are indispensable . Especially in the first three phases, the first phase of the operation is completed properly, a direct impact after the implementation phase of the work. Therefore, when aerial refueling, must be based on different situations of the various stages, each stage of the operation a solid job, the successful completion of each stage. Due to the different air refueling equipment, refueling specific work of the various stages there are differences. In organizing the implementation of aerial refueling, depending on the circumstances require, with suitable methods adopted to ensure the smooth implementation of the aerial refueling process. The following focuses on the use of aerial refueling hose refueling system process.

Air refueling process is longer, by oil and other special airplane pilot to be patient and focus on keeping flight. No special circumstances, a fuel tank of the aircraft should be filled after the end of the refueling process, under exceptional circumstances, should the commander's command promptly interrupt the refueling process in order to give the other in case of emergency need to add fuel aircraft for aerial refueling. In this case, refueling with refueling aircraft should immediate contact with communication, exchange information.

Compared to other stages of aerial refueling, the exit stage than in previous stages of the action to be simpler, but also much easier, but it can not be ignored, especially in the case of continuous aerial refueling, it must be closely coordinated action to strengthen aerial observation . In need of emergency from the refueling position, giving way to other aircraft refueling especially when, otherwise it will affect safety.

Refuel at night, its refueling with the same daytime, but at night light logo Can rely on tanker docking, more difficult. 


\section{References}

[1] Joseph P N, Jacob L H. Automated aerial refueling: extending the fectiveness of unmanned air vehicles.

[2] L. Soft autonomous aerial refueling refueling aircraft flight control technology research [MS Thesis]. Nanjing University of Aeronautics and Astronautics,

[3] G.J. UAV aerial refueling rendezvous white master controller design [A]. Control and Decision,

[4] Hong Koon. Study air refueling schedule. Flight Mechanics, 1997

[5] SunJinBiao.Most optimization problems aerial refueling flight mechanics. 